\title{
CIÊNCIA EM DEBATE: JORNALISMO CIENTÍFICO NAS ONDAS DO RÁDIO
}

\section{Programa de rádio abre espaço para o jornalismo científico e estabelece diálogo descontraído com seu público}

O público brasileiro dos meios de comunicação de massa (rádio, televisão, jornal e revista) demonstra um especial interesse em matérias jornalísticas de ciência, com destaque para aquelas que são voltadas para a área de saúde.

As matérias de ciência têm um papel social de grande importância, principalmente em um país como o Brasil, marcado por diferenças sociais que relegam grande parcela da população à pobreza quase que absoluta. As informações de uma boa matéria de divulgação científica têm o poder, por exemplo, de reduzir a mortalidade infantil, resgatar direitos, prestar esclarecimentos sobre eles e levar a população a ter acesso ao conhecimento científico que se produz no país e no mundo. Permite, ainda, que a ciência se incorpore à vida, não como uma entidade à parte, mas como algo integrante do cotidiano da população.

No entanto, nem sempre o jornalista brasileiro está apto a cobrir ciência. Mesmo porque a sua visão de ciência ainda é calcada na visão positivista, o que o leva a dar mais ênfase às pesquisas desenvolvidas em áreas restritas de exatas e biológicas, com um discurso difícil e elitizado. Desta forma, o jornalista assume o papel do semideus Mercúrio que leva para os mortais a mensagem dos deuses, no caso os cientistas.

Esta visão conservadora só faz criar uma barreira que impede a interação com o leitor, o ouvinte e o telespectador. Cabe ao jornalista lembrar ao seu público que a ciência está totalmente incorporada à vida e que as benesses dela devem chegar a toda a sociedade.

A partir da percepção de que os meios de comunicação social no Brasil ainda dedicam pouco espaço à ciência, apesar do grande interesse que muitas matérias relacionadas à ciência despertam no público de uma maneira geral, idealizei, em 1996, um tipo de programa radiofônico voltado totalmente para a área

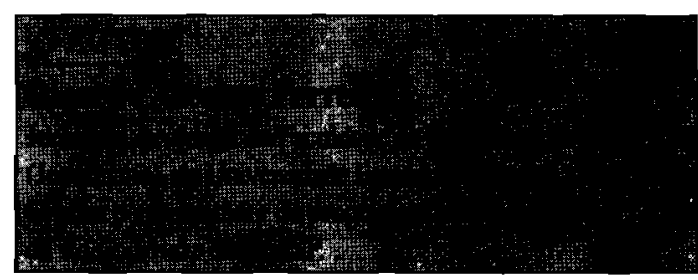


jornalístico-científica. ${ }^{1}$ Trata-se do programa Ciência em Debate, veiculado na Rádio Unesp-FM, na cidade de Bauru, região centro-oeste do Estado de São Paulo. O programa teve como característica divulgar a produção científica - nas áreas das ciências humanas, biológicas e exatas - desenvolvida por pesquisadores da Unesp (incluem-se nesta categoria, além dos docentes e pós-graduandos, alunos de graduação que tenham defendido trabalhos de final de curso ou iniciação científica), docentes e pesquisadores de outras instituições de ensino e pesquisa.

O Ciência em Debate esteve no ar de agosto de 1996 a março de 1999, tendo uma grande receptividade da comunidade Unesp, bem como dos demais ouvintes da Rádio Unesp-FM. A Universidade Estadual Paulista é uma das mais importantes universidades públicas brasileira. Ela foi criada em 1976 e reúne 24 faculdades e institutos, centros de estudo e unidades especiais, que oferecem formação em 47 carreiras, num total de 81 cursos de graduação, 92 de mestrado e 67 de doutorado. Envolvendo um total de 25 mil alunos. Uma das características da Unesp é a distribuição dos seus 18 campi por quase todo o Estado de São Paulo.

Enquanto diretor e apresentador do Ciência em Debate, entendo a ciência como algo dinâmico e que só faz sentido quando contextualizada no meio social. Desta forma, toda a pesquisa, ao ser abordada no Ciência em Debate, ligava-se com os assuntos atuais, dando possibilidade ao ouvinte de entender a ciência como parte integrante do seu cotidiano e de visualizar a produção universitária e a própria universidade não como algo distante, mas como uma entidade próxima, produtora e reelaboradora do saber.

\section{DIVULGAÇÃO CIENTÍFICA NO RÁDIO}

Não se pode dizer que exista uma fórmula específica para a divulgação de ciência. Mas existem alguns pré-requisitos que podem levar esta empreitada a dar certo. A primeira é o profissional de comunicação ter bem definido o que é ciência. Neste caso, ele deve entender que ciência é um bem social e, portanto, deve ser também divulgado enquanto algo acessível ao maior número de pessoas. Outro dado importante é o conhecimento que o profissional deve ter do processo de construção do pensamento científico. Conhecer metodologia científica e conseguir 
contextualizar os fenômenos são elementos imprescindíveis para o jornalista ou comunicador que quer se aventurar no universo da ciência.

A principal proposta do programa Ciência em Debate foi levar até o ouvinte aquilo que é debatido no campus universitário. Privilegiou-se o momento em que o ouvinte podia sentir-se em diálogo com o pesquisador que era provocado a contar suas experiências, seu conhecimento sobre determinado assunto como se estivesse em um bate-papo descontraído com os ouvintes. O programa seguia o formato jornalístico de entrevista (diálogos), intercalado por músicas escolhidas pelo próprio pesquisador. A inserção da música tinha por objetivo humanizar a figura do pesquisador, que poderia demonstrar, além de seu lado profissional, seus gostos, suas opções como cidadão comum e seus sentimentos que, muitas vezes, podem até ter influenciado o seu interesse por este ou aquele assunto pesquisado. Não raras vezes, o pesquisador pôde confessar aos ouvintes as suas motivações para ter se dedicado a determinado tema, ligado a alguma expectativa ou à necessidade de superar dúvidas ou dificuldades de cunho mais existencial. Foram vários os assuntos abordados pelo Ciência em Debate, tais como Lixo Urbano, Ensino, Jornalismo, Globalização, Homossexualidade, Inteligência Artificial, Literatura Portuguesa, Semiótica, Violência, Polícia Militar e vários outros temas de interesse acadêmico e social.

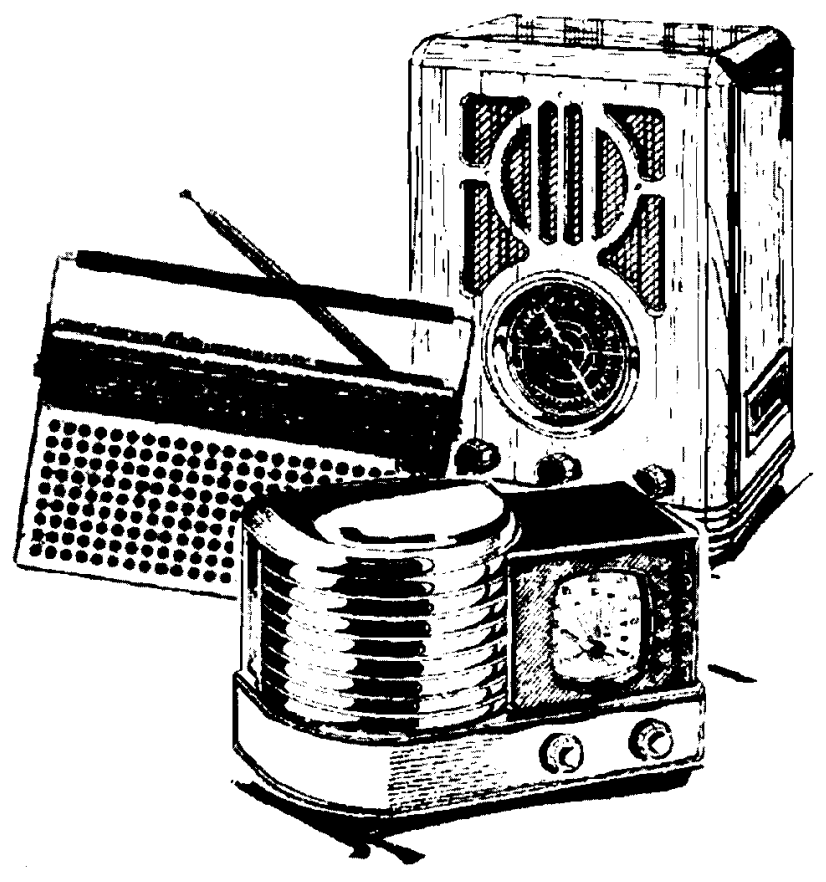




\section{INFORMAÇÃO JORNALÍSTICA}

A primeira pergunta que deve ser formulada ao pensar em jornalismo especializado é se realmente existe jornalismo especializado.

Wílson da Costa Bueno, citando Otto Groth, caracteriza o jornalismo por alguns princípios básicos como universalidade, periodicidade, atualidade e difusão coletiva. Para ele, estes elementos juntos é que vão possibilitar a compreensão do fenômeno jornalístico ${ }^{2}$.

Esta também é a posição de Edvaldo Pereira Lima. Para o autor, "o jornalismo serve ao propósito de informar e orientar sobre fatos da atualidade, mantendo um vínculo de contato periódico com a audiência, que é dispersa geográfica e socialmente, tratando de temas que dizem respeito aos mais variados campos do saber humano"3.

Portanto, o que se pode afirmar é que existem jornalismos, que podem atuar ou cobrir algumas áreas específicas, mas preservando a sua principal característica que é a informação. Assim, não é possível se falar em um jornalismo especializado, mas sim de jornalismos que vão cobrir áreas especializadas.

Nessa concepção, informar significa passar ao leitor o maior número de dados quantitativos e qualitativos, para que ele possa reconstruir a realidade de um fato. É evidente que ao estar informando, o jornalista também está reelaborando a sua realidade e está passando a sua versão do fato.

A linguagem jornalística prima por ser direta, informativa e rica em detalhes relevantes. No entanto, o texto jornalístico é muito mais que lide, sublide ${ }^{4}$, desenvolvimento e conclusão - formas tradicionais de se fazer um texto jornalístico -, envolvendo as famosas pirâmides inverti$\mathrm{da}^{5}$ e normal. Ele também pode ser carregado de elegância e estilo próprios do jornalista, mas deve garantir a linguagem jornalística básica e responder, não importa se no primeiro parágrafo ou no decorrer do texto, às questões básicas da informação (o quê?, quem?, quando?, onde?, como? e por quê?). No caso de meios eletrônicos, o texto jornalístico pode utilizar outros recursos criativos com o intuito de melhor informar.

A primeira necessidade, ao se estar fazendo uma publicação ou programa específicos, é o conhecimento do público a que se destinam, para poder adaptar a informação jornalística a parâmetros mais maleáveis e acessíveis ao leitor, ao ouvinte ou ao telespectador. Assim, por exemplo, quando se tem uma publicação ou programa, vol-

2. BUENO, Wíson da Costa. Ojornalismo como disciplina científica: a contribuição de Otto Groth. São Paulo, ECA-USP, 1972. (mimeo.) 3 LIMA, Edvaldo Pereira. Páginas ampliadas: o livro reportagem como extensâo do jornalismo. Campinas: Unicamp, 1993. p. 21. 4. Lide é o primeiro parágrafo de uma notícia. Ele deve trazer as principais informações que tratam sobre o quê, por quê, como e onde aconteceu o fato. O sublide é o parágrafo seguinte ao lide. Ele complementa as informações que não foram dadas no lide. 5. Pirâmide invertida é o termo jornalístico que se refere à estrutura da notícia, ou seja, trata da disposição das informações em ordem decrescente de importância. Esse procedimento permite, quando há necessidade de corte de texto, a supressão dos últimos parágrafos sem grande perda para o leitor. 
tados para um público de adolescentes, pode-se fazer todas as formas de peripécias na diagramação ou na formatação.

Então, a pergunta correta é: e a linguagem deve ser diferente? Sim, a linguagem muda, mas ela não pode ser fechada em jargões. Se ficar incompreensível para o público que não faz parte daquela tribo, então, o texto pode ser tudo, menos jornalístico.

No caso de um projeto que envolverá um público de um universo comum, como por exemplo um hospital, mas na essência heterogêneo partindo do princípio de que dentro deste hospital existe desde a faxineira até o médico -, então a linguagem jornalística sóbria é o melhor recurso.

Os modelos que podem ser adotados, neste caso, são as revistas de circulação mensal ou semanal e, mesmo, os jomais diários ou os programas jornalísticos da mídia eletrônica. Pois eles atendem um leitor heterogêneo, atingindoo com um tipo de produção que é possível de ser assimilada por todos.

A produção especializada, ou voltada para temas especializados, pode ser perfeitamente adaptada e depende da criatividade do jornalista, do tom diferenciado e de um texto mais agradável. Mas sem deixar de preservar o princípio jornalístico da informação.

Durante mais de dez anos, tenho feito, enquanto jornalista, coberturas nas diferentes áreas de ciência. Nestes anos de experiência fui o jornalista-responsável, por mais de quatro anos, da Revista da APCD, uma publicação especializada da área de Odontologia, que tem uma tiragem de 45 mil exemplares e é considerada a mais importante publicação da área odontológica da América Latina, tendo escrito todas as matérias de capa desta publicação.

Também trabalhei em publicações como o Jornal da USP (veículo de comunicação da Universidade de São Paulo) e também na assessoria de imprensa do Gabinete do Reitor da USP, em 1992 e 1993, com o objetivo de transformar os resultados das pesquisas dos docentes e pesquisadores da USP em matérias de interesse jornalístico. Em minha trajetória profissional posso citar também a experiência como jornalista nos jornais $O$ Estado de $S$. Paulo e Jornal da Tarde.

$\mathrm{Na}$ verdade, tenho consciência de que o produto jornalístico voltado para ciência não vai diferir dos demais. É ilusão achar que o jornalista que cobre ciência tem de estar em níveis de superioridade em rela- 
ção aos demais profissionais da imprensa. O que se exige deste profissional é responsabilidade social e rigor na apuração dos dados, além de preparo para lidar com o tipo de informação diferenciada que deve disponibizar ao público. Estes requisitos, no entanto, não são exclusividade dos jornalistas que cobrem ciência, mas devem ser imprescindíveis para qualquer jornalista, de qualquer área.

Resumo: $\mathrm{O}$ depoimento apresentado neste artigo tem por objetivo mostrar como é possivel conseguir um diálogo entre o cientista-pesquisador e o jornalista. A experiência do programa radiofônico Ciência em Debate, veiculado pela Rádio Unesp$F M$, em Bauru, região centro-oeste de São Paulo, de 1996 a 1999, mostrou que é possivel fazer da entrevista científica um diálogo e, também, humanizar o cientista-pesquisador. Com isso os jargões do cientista-pesquisador, marcados muito mais como um mecanismo de defesa ou de superioridade, vão sendo paulatinamente substituídos por uma explicação simples, sem perder a complexidade. A experiência do Ciência em Debate foi, antes de tudo, a democratização e a ampliação do saber como um bem público.

Palavras-chave: rádio, jornalismo científico, jornalismo especializado, Ciência em Debate, Unesp
Abstract: The testimony presented in this article aims at showing how it is possible to reach dialogue between the scientist-researcher and the journalist. The Ciência em Debate (Science in Debate) radio program's experience, broadcast by Rádio Unesp-FM, in Bauru, Midwestern São Paulo State, between 1996 and 1999, showed that it is possible to turn scientific interviews into dialogue and, also, humanize the scientist-researcher. By doing this, the scientist-researcher's jargon, marked much more as a defense or superiority mechanism, has been slowly substituted by simple explanations, without any loss in complexity. The Ciência em Debate experience was, most of all, the democratization and enhancement of knowledge as part of the public wealth.

Key words: radio, scientific journalism, specialized journalism, Ciência em Debate, Unesp 